\title{
Effects of Sugars on the Drying Of Some Local Fruits and Their Importance on Baked Products-Bread and Cake
}

\author{
${ }^{1}$ Kabuo, N.O., ${ }^{2}$ Onuegbu, N.C., ${ }^{3}$ Nwosu, J.N., ${ }^{4}$ Peter-Ikechukwu. A.I., \\ ${ }^{5}$ Udeozor, L.O., and ${ }^{6}$ Howells-Nworie, I.C \\ 1,2,3,4,5 Department of Food Science and Technology Federal University of Technology, P.M.B. 1526, Owerri, \\ Imo State Nigeria
}

\begin{abstract}
The effect of sugars on the drying of some local fruits (pineapple, pawpaw, and banana) and their importance on baked products (bread and cake) were investigated. The fresh fruits were washed with clean water, peeled, sliced, and soaked in different sugar solutions (glucose, sucrose and maltose). After $8 \mathrm{~h}$ the fruit slices were drained off the sugar solution, then placed in trays and dried in a moisture extraction oven to a constant weight. After drying, the dried fruits were allowed to cool and then packaged in bottles with cover. The mixed dried fruits were packaged according to the treatment with the sugar solution. The mixed dried fruit samples were tested organoleptically and compared with mixed dried fruits sold in the market for colour, aroma, taste, texture, and chewiness at a 9-point hedonic scale. These mixed dried fruits were also used in the baking of bread and cakes, and the mixed dried fruits obtained from the market served as control. Results show that mixed dried fruits treated with sucrose solution were a close substitute for the mixed fruits sold in the market. For according to the panelists, there were no significant $(p<0.05)$ difference between control and dried fruits treated with sucrose solution in all parameters tested. In the production of nutritional bread and cakes, the use of these dried fruits increased the organoleptic properties. Treatment with sugar solutions are recommended for drying of fruits because they reduce nutrient loss and drying time.
\end{abstract}

Key words: baked products, drying, mixed fruits, organoleptic properties, sugars.

\section{Introduction}

Dried fruits are fruits in which the majority of the original water content has been removed either naturally, through sun drying, or dehydrators (Falade and Aworh, 2005). Drying of fruits is developed to preserve quality characteristics such as flavour, colour, appearance and texture as closely as possible to those of fresh fruits. Sun drying is preferred because it is abundant, inexhaustible, cheap and environmental friendly (Basunia and Abe, 2001). High losses are experienced during the seasonal glut because of poor postharvest handling practices and low level of utilization of these fruits. Preservation of these fruits by any economical technique becomes important in the tropics. All dried fruits provide essential nutrients and an array of health protective bioactive ingredients making them valuable tools to both increase diet quality and help reduce the risk of chronic diseases (Figuerola et al., 2005). The combination of nutritional value and enjoyable taste is the reason dried fruits have been popularly considered a healthy food for millennia. Dried fruits are naturally resistant to spoilage and are easy to store and transport, and relatively low in cost. They are also a convenient way to increase the number of servings of fruits in diet (Venti, 2002). Fruits can be dried through a process known as dehydration which removes enough moisture from the fruit to retard the growth of bacteria and mold while retaining the great taste and nutrients, as well as increase the shelf life of the fruit (Hui, 2006). The two most popular methods used to dehydrate fruits are sun drying and tunnel drying. The tunnel dryer is preferred because it reduces contamination of the fruits by insects, dusts, and pests when spread to dry under sun. The use of sugars reduces these difficulties, as it prevents the loss of water soluble vitamins, and phytochemicals along with the water (Williamson and Carughi, 2010).

The main nutrients found in fruits are minerals and vitamins which are needed by the body to maintain efficient body functioning (Venti, 2002). These nutrients include: Potassium, dietary fibre, vitamin C and folate (folic acid). Dried fruits have more calories and natural sugars because the dehydration process removes so much of the water normally found in the fruit, so that the calorie from $10 \mathrm{~g}$ of fresh pawpaw is not the same in $10 \mathrm{~g}$ of dried pawpaw.

Dried fruits can be used for different purposes. It can be eaten as a snack/desert; it can be reconstituted and used to make soups. It can also be used as varnishes, sauces, puddings and in enrichment of bread, cakes, as well as confectioneries (Sudha et al., 2007). This is to enhance the quality, sensory and nutritional value of the baked products.

In Nigeria, all the dried fruits used in bakery and confectionery industries are imported from other countries. This reduces the nation's foreign reserve. Also there is a huge loss of fruits and revenues during the seasonal gluts of fruits, due to postharvest losses, as there are no storage and preservative facilities for these 
fruits. This in turn discourages farmers to produce more fruits as they hardly get enough money from sale of fresh fruits.

The objective of this work therefore includes:

1. To determine the effects of some sugars in treatment and drying of some local fruits (pawpaw, pineapple and banana).

2. To compare the organoleptic characteristics of the mixed dried local fruits with the mixed dried fruits obtained from the market, and

3. To determine the acceptability of bread and cake produced with the mixed dried local fruits.

It is hoped that this work on dried local fruits will compare favourably with their imported counter parts which will help to reduce the amount spent on importation of dried fruits for bakery and confectionery industries; food processors will be encouraged to use the local fruits in the production of quality mixed dried fruits that could be used both as snack and in the bakery and confectionary industries and this will also reduce the quantity of postharvest losses of fruits during the seasonal gluts. Also farmers will be encouraged to boost production of fruits, as well as value addition both for the fruits and the baked goods.

\section{Materials And Method}

\section{Materials Procurement}

Mature, ripe pawpaw, pineapple, banana, wheat flour, yeast, shortening, baking powder, salt, and dried fruits were purchased from a local market in Owerri, Imo state.

The sugars (sucrose, glucose, and maltose), moisture extraction oven, aluminum tray, knife, bowl, electronic digital balance, crucible, muffle furnace, conical flask, pipette, carbonizer used were obtained from the laboratory of the Department of Food Science and Technology, Federal University of Technology, Owerri.

\section{Preparation of the Sugar Solution (osmotic solutions)}

The glucose, sucrose, maltose solution were prepared by dissolving $300 \mathrm{~g}$ of their solid particle in $300 \mathrm{~g}$ of water at $40^{\circ} \mathrm{C}$ in a water bath for $30 \mathrm{~min}$.

\section{Preparation of the Fruits}

The fruits were separately sorted (to remove the soft ones), and then washed with water (to remove dirt's and dust), the wash water on the fruits were allowed to drain, the clean fruits were peeled (to remove the hard covering) and cored (to remove the hard centre) and seeds removed where necessary; and then sliced to the desired size.

\section{Treatment of Fruit Slices with the Osmotic Solutions}

This was done using a modified method described by Panagiotu et al. (1998). The fruit slices were treated with freshly prepared sugar solutions in the ratio of 1:4 (w/w: sugar solution: fruit slices). The fruit slices were soaked in the sugar solutions for $8 \mathrm{~h}$; the samples were removed from the sugar solutions and allowed to drain to remove adhering sugar solution.

\section{Drying of the Fruit Samples:}

The treated samples and the control (untreated fruit slices) were dried in a moisture extraction oven at temperature of $60^{\circ} \mathrm{C}$ for $6 \mathrm{~h}$, with adequate air distribution to maintain low humidity. The drying time and rate were determined, and also moisture losses were determined at a constant weight. This was achieved by weighing the sample every $2 \mathrm{~h}$ for $6 \mathrm{~h}$ until the constant weight was achieved (that is the point at which there was no further loss of water).

\section{Determination of the Yield of the Dried fruit Samples:}

The yield of the dried fruit samples were determined from the peeling yield, slicing yield, quantity of sugar solution absorbed and so on.

\begin{tabular}{|c|c|c|}
\hline$\%$ peeling loss of fruit $=$ & Weight of peel & X $\underline{100}$ \\
\hline & Weight before peeling & 1 \\
\hline jield of fruit & Weight after slicing & $\mathrm{x} \underline{1}$ \\
\hline & Weight before slicing & \\
\hline
\end{tabular}

Quantity of sugar absorbed after blotting $=\mathrm{W}-$ Wo 
Where, $\mathrm{W}=$ weight of sliced fruits after osmotic dehydration

Wo= weight of sliced fruits prior to osmotic dehydration

$\%$ drying yield of fruit $=\quad \frac{\text { Weight after drying }}{\text { Weight before drying }} \times \frac{100}{1}$

Proximate Analyses of Dried Fruit Samples:

The proximate analyses on fruit samples were carried out to determine the compositions of the fruits and their respective proportions.

\section{\% Moisture Content Determination}

This was determined using the method adopted by A.O.A.C., (1990) and Nielsen, (2003). Aluminum moisture can was thoroughly washed with water and detergent, dried in the moisture extraction oven, cooled in desiccators and then weighed with digital balance. Five grams of the individual (pineapple, pawpaw, and banana) samples were weighed into the previously cleaned and weighed moisture can. It was dried in the moisture extraction oven at the temperature of $105^{\circ} \mathrm{C}$ for $8 \mathrm{~h}$. It was removed and cooled in a desiccator, and then reweighed. The sample was returned to the oven and dried further, weighed after every $2 \mathrm{~h}$ until the constant weight of the sample was achieved. The percentage moisture content was calculated as described in the equation below:

$\%$ moisture content $(\mathrm{MC})=\underline{\text { weight } \text { of moisture evaporated }} \times \underline{100}$

$$
\text { Weight of sample }
$$

\section{\% Ash Content Determination}

The ash content was determined as described using the method adopted by Onwuka, (2005). Five grams of sample was weighed with the electronic digital balance into a porcelain crucible. The sample was charred on a Bunsen flame into a pre-heated carbonite shield muffle furnace at temperature of $550^{\circ} \mathrm{Cfor} 2 \mathrm{~h}$ until a white or light gray ash was achieved. When the residue turned black color, it was moistened with small amount of water to dissolve salts, dried in an oven and the process repeated. It was then cooled in dessicator, reweighed and calculated as percentage ash content.

$\%$ ash content $=\underset{\text { Weight of original sample }}{\stackrel{\text { weight of ash }}{1}} \times \frac{100}{1}$

\section{\%Fiber content determination}

This was determined by the method adopted by James, (1995) and Onwuka, (2005). A measured mass of each ground sample $(2 \mathrm{~g})$ was defatted (as in the fat analysis). The defatted sample was boiled under reflux for $30 \mathrm{~min}$ with $200 \mathrm{ml}$ of solution containing $1.25 \mathrm{~g}$ of tetraoxosulphate (VI) per $100 \mathrm{ml}$ of solution. The solution was filtered through linen cloth on fluted funnel and washed with boiling water until the washing was no longer acidic. The residue was transferred into a beaker and boiled for $30 \mathrm{~min}$ until $200 \mathrm{ml}$ of a solution containing $1.25 \mathrm{~g}$ of carbonate free $\mathrm{NaOH}$ per $100 \mathrm{ml}$ was obtained. The final residue was filtered through a thin but close pad of washed and ignited asbestos in a crucible, dried in an electric oven at $105^{\circ} \mathrm{C}$ for an hour. It was cooled in a dessicator and weighed. It was then incinerated in a muffle furnace, cooled in a dessicator and weighed again. The fibre was determined as follows;

$\%$ fibre content $=\underline{\mathrm{W} 2}-\mathrm{W} 3 \mathrm{X} 100$

W2-W1 1

Where, $\mathrm{W} 1=$ weight of crucible

W2 = weight of crucible + sample after drying in oven

W3 $=$ weight of crucible + sample after ashing

\section{\%Fat Content Determination}

The fat content was determined by soxhlet extraction method as described by Onwuka, (2005).

A $250 \mathrm{ml}$ clean boiling flask was dried in the moisture extraction oven at the temperature of $105^{\circ} \mathrm{C}$ for $30 \mathrm{~min}$, then transferred into a dessicator and allowed to cool. Five grams of sample was weighed accurately using electronic digital balance into labeled filter paper and wrapped. Corresponding labeled, cooled, round bottle flask was also weighed. The flask was also filled with $120 \mathrm{ml}$ of petroleum ether (boiling point $40^{\circ} \mathrm{C}-60^{\circ} \mathrm{C}$ ) and the wrapped sample put on the sample holder. Soxhlet apparatus was assembled and heated on the heating 
mantle for $6 \mathrm{~h}$, the spent sample was removed from the holder, apparatus was reassembled and the solvent was recovered by distillation leaving the fat in the flask. The apparatus was dismantled again and the sample (fat) in the flask was dried at $105^{\circ} \mathrm{C}$ in the moisture extraction oven for $1 \mathrm{~h}$, and then transferred from the oven into a dessicator, allowed to cool, reweighed and then calculated as:

$$
\% \text { fat content }=\underset{\text { Weight of sample }}{\text { Weight of fat }} \times \frac{100}{1}
$$

\section{Bread Production}

The straight dough method described by Eggleston, et al. (1993) was followed. The recipe according to Iwe (2002) was used in the bread production (Table 1). All ingredients used in baking the bread were manually homogenized together until soft dough that can easily be handled was produced. The whole mass was kneaded mechanically, divided into equal sizes and then manually kneaded prior to molding into cylindrical shape and placed in the lubricated bread baking pan. Dough was allowed to proof for $30 \mathrm{~min}$ in a warm chamber. After proofing, the dough was brought out and then put in an oven to bake at a temperature of $240^{\circ} \mathrm{C}$ until done, after which it was withdrawn from the oven, depanned and then allowed to cool. The flow diagram for the production of bread is shown in fig. 1 .

\section{Production of Cake}

The ingredients, fat and sugar were homogenized using the creaming method until fluffy, (i.e soft, light and full of air). Eggs which have been whisked was then added and mixed by cutting. The flour, baking powder, dried fruits, and flavor were then added and mixed to obtain a soft batter. The batters were then put into greased cake pans and then put into the oven and baked at $170^{\circ} \mathrm{Cfor} 1 \mathrm{~h}$. The cakes were depanned, cooled and packaged.

\begin{tabular}{lc} 
Table 1: Recipes for the production of bread \\
\hline Material & Composition (\%) \\
\hline Wheat flour & 100 \\
Salt & 1.5 \\
Sugar & 2.0 \\
Yeast (instant dry yeast) & 1.6 \\
Shortening & 1.0 \\
Water & varies \\
Fruit & varies \\
Source: (Iwe, 2002) & \\
\hline
\end{tabular}

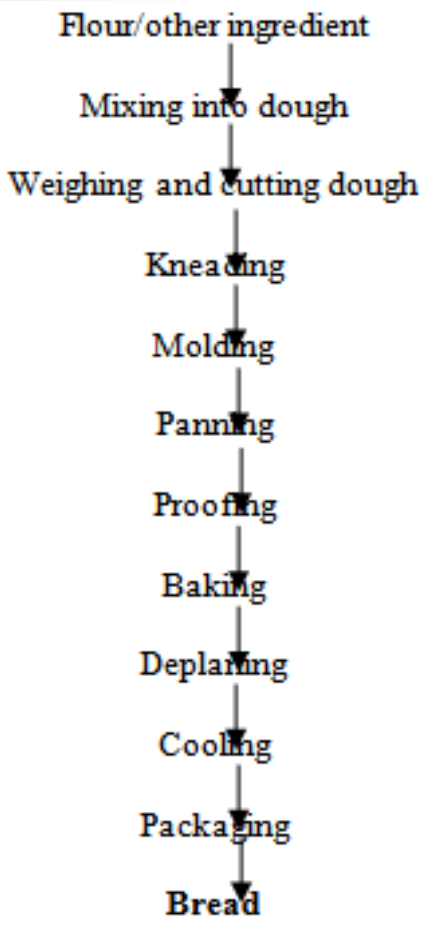

Fig.1: flow diagram for the production of bread 


\section{Sensory Evaluation}

The sensory qualities of the bread and cake were evaluated by 20 panelists drawn from the University community using a nine-point hedonic scale - where 9=extremely liked ... and 1= extremely disliked (Ihekoronye and Ngoddy, 1985). The products were given to the panelists in coded forms and the panelists were given some privacy in order to avoid being biased by others. The panelists were given water to rinse the mouth after chewing each sample. The samples were evaluated for colour, aroma, taste, texture, chewiness, mouth feel and overall acceptability.

\section{Peeling yield of the fresh fruits:}

\section{Result And Discussion}

The fruit had different peeling yield due to the thickness/ weight of their peels (Table 2). Banana had the highest \% peeling loss $(40.72 \%)$ but the lowest slicing loss $(0.40 \%)$. This was because the weights of the peel were high, but during slicing the fruits exuded little or no juice. Pawpaw had a moderate loss of weight $(21.17 \%)$ on the peels and only $(0.80 \%)$ during slicing which also meant that minimal juice was lost during slicing. Pineapple had the least peeling loss (13.07), but its slicing loss was relatively higher (5.72\%) than those of banana $(0.40 \%)$ and pawpaw $(0.80 \%)$. This was due to the fact that pineapple was very juicy and much of the juice exuded from the fruit during slicing and hence the high slicing loss. Despite the high slicing loss of pineapple, it gave the highest total weight $(81.21 \%)$ of fruit after peeling and slicing, while banana gave the least $(58.88 \%)$ [Table 2]. The slicing process had no significant effect on the \% yield of the fruits. Also the size of fruit slices affected the degree of expression of juice. Pineapple was more fibrous than the other fruits (banana and pawpaw) which tend to cleave to the kitchen knife during slicing and more juice was expressed. Also the total loss from peeling and slicing pineapple was far lower than even the paw-paw and banana which contributes its high weight after peeling and slicing.

Table 2: The \% peeling loss, slicing loss and total weight of Fresh Fruits after peeling and slicing

\begin{tabular}{lccc}
\hline Fresh fruit samples & \%peeling loss & \%slicing loss & \%total weight after peeling and slicing \\
Pineapple & 13.07 & 5.72 & 81.21 \\
Pawpaw & 21.17 & 0.80 & 78.03 \\
Banana & 40.72 & 0.40 & 58.88
\end{tabular}

The determination of the \%peeling yield is necessary both to the household and commercial users because;

- It enables the commercial and household users to be able to determine the right amount of the edible portion of fruits required for the desired operation, and

- 2. It enables the commercial users to be able to determine the amount of waste that will be accumulated and the cost of disposing them off.

\section{Percentage Drying Yield of the Fruits}

Table 3 shows that the percentage drying yields for the control samples were lower than the sugar treated samples, except in the sample treated with maltose. Also the banana samples had highest percentage drying yield on both the treated samples and control, than the rest of the dried samples. This high percentage drying yield of banana could be due to the fact that banana had more total solid than the other fruits. The percentage drying yield $(13.98 \%)$ for pineapple (control) in this work was approximately the same with what was reported in literature $(14.00 \%)$ on (http://www.philippineherbalmedicine, 2011). The difference was very negligible and could be due to handling. Comparing the value of the control (not treated with sugar solution) banana fruit $(20.76 \%)$ sample, with the value of the banana fruit $(25.60 \%)$ uploaded on net, this could be either due to difference in the species varieties of banana fruits used or due to the difference in the degree of dryness desired during the drying process.

Table 3: The \%drying Yield of the Untreated and Treated Dried Fruit Samples

\begin{tabular}{lccc}
\hline Treatment & \multicolumn{3}{c}{ Fresh fruit sample } \\
& Pineapple & Pawpaw & Banana \\
\hline Not treated with sugar (control) 13.78 & 13.98 & 20.76 \\
Glucose & 17.30 & 17.90 & 21.05 \\
Sucrose & 21.42 & 22.50 & 23.88 \\
Maltose & 10.28 & 11.85 & 18.90 \\
\hline
\end{tabular}




\section{Proximate Composition Of The Fruit Samples}

\section{Effect of Sugar Solution on the Moisture Content of the Fruits}

The moisture content of the untreated (control) fruit samples was higher than moisture content of the fruit samples treated with different sugar solutions, except for the fruit samples treated with maltose which was higher than the control. The different fruit samples treated with sucrose solution had the lowest moisture content. In both the control (untreated) and the different treated fruit samples, it was noticed that their pineapple samples had higher moisture content, with banana fruit sample having the lowest moisture content. The difference between the moisture content of the pineapple (86.21\%) fruit sample and the pawpaw $(86.01 \%)$ fruit sample were very low (i.e. $0.20 \%$ ), compared to the banana(79.22\%) fruit sample which had a slight difference from both pawpaw and pineapple fruit samples respectively. This showed that the pawpaw fruit sample and the pineapple fruit sample had more water contents than the banana fruit sample.

The percentage moisture of the different fruit (pineapple, pawpaw, and banana) samples in both the control (not treated with sugars), and glucose, sucrose, and maltose (sugar solutions) respectively, were given in an increasing order as: Banana fruit > pawpaw fruit > pineapple fruit.

While the degree of the effect of the different sugar solution treatment on the fruit samples, is written in its increasing order as: Sucrose solution > glucose solution > maltose solution.

The keeping qualities of fruits are affected by the moisture content. The higher the moisture contents of the fruits the shorter the keeping quality and vice versa. From the table above, the quantity of moisture given out by the fruit samples treated with sucrose solution was lower than the fruits treated with glucose and maltose sugar solution. But it was observed that the keeping quality of the dried fruit samples treated with sucrose was not affected compared to the other samples. This could be because of the hygroscopic (moisture absorption) nature of the sucrose solution as it binds the water molecules within, making them unavailable for microbial spoilage.

\section{Percentage Ash Content of the Fruit Samples}

The ash content of the untreated (control) dried fruit samples was higher than the ash content of the treated dried fruit samples (Table 4). The control samples showed that the dried banana (2.82\%) sample had higher ash content than the pawpaw (2.67\%) and pineapple (2.18\%) samples. It was the same trend that was observed for samples treated with glucose, sucrose, and maltose solutions. The reason could be that banana sample contained more minerals (sodium, potassium, calcium, magnesium, and so on) than the other fruit samples.

\section{Percentage Fiber Content of the Dried Fruits}

Dried pineapple $(2.60 \%)$ fruit sample has the highest fiber content, followed by the dried pawpaw (2.53\%) fruit sample, and then the dried banana (2.50\%) fruit sample, in the control (untreated dried fruits) samples (Table 4). This trend was also observed for the other dried fruit samples treated with glucose, sucrose, and maltose solutions.

Dried pineapple samples (both in the control and treated samples), had the highest fiber contents, than the other dried fruit samples. Dried banana fruit samples had the lowest fiber value. This showed that the dried pineapple fruit samples had a lower Glycemic index than the dried pawpaw and banana fruit samples. Foods with high fiber content generally have a low GI (Kim, 2008).

\section{Percentage Fat Content of the Fruit Samples}

All the fruit samples had negligible fat content.

Table 4: Proximate composition of the fruit samples

\begin{tabular}{lccc}
\hline Fresh fruit samples/ treatment & \multicolumn{3}{c}{ Proximate composition } \\
& Moisture content $(\%)$ & Crude fibre content $(\%)$ & Ash content (\%) \\
\hline Pineapple (untreated) & 86.21 & 2.60 & 2.18 \\
banana (untreated) & 79.22 & 2.50 & 2.82 \\
Paw-paw (untreated) & 86.01 & 2.53 & 2.67 \\
Pineapple (glucose) & 82.69 & 2.47 & 1.28 \\
Banana (glucose) & 78.57 & 2.20 & 2.60 \\
Paw-paw (glucose) & 82.00 & 2.38 & 1.96 \\
Pineapple (sucrose) & 78.57 & 2.32 & 1.32 \\
Banana (sucrose) & 76.11 & 2.16 & 2.67 \\
Paw-paw (sucrose) & 77.43 & 2.20 & 1.90 \\
Pineapple (maltose) & 89.63 & 2.65 & 2.00 \\
Banana (maltose) & 81.08 & 2.53 & 2.75 \\
Paw-paw (maltose) & 88.15 & 2.59 & 2.27 \\
\end{tabular}


Effects of Sugars on the Drying Of Some Local Fruits and Their Importance on Baked Products-

\section{Organoleptic Characteristics Of The Dried Fruit Samples And The Baked Products} Organoleptic Characteristics of Mixed Dried Fruit Samples

The overall acceptability of the control and the dried fruits treated with sucrose were the same (i.e moderately liked), followed by the dried fruits treated with glucose and those treated with maltose was least. The colour of the control and sucrose treated dried fruits were the same in aroma but with a slight $(p<0.05)$ difference in their texture, chewiness and mouth feel (Table 5). The taste of the dried fruits treated with sucrose and glucose were significantly $(\mathrm{p}>0.05)$ similar to the taste of the control (score approximately 7.0 i.e moderately liked). The dried fruits treated with sucrose could serve as a close substitute to the mixed fruits sold in the market according to the panelists (Table 5) as there were no significant $(\mathrm{p}<0.05)$ difference between the two samples in all sensory attributes tested. Dried fruits treated with maltose had the least score in all the sensory attributes evaluated.

Table 5: The Mean Score for Sensory Attributes of Mixed Dried Fruit Samples and Control (mixed dried fruit from the market)

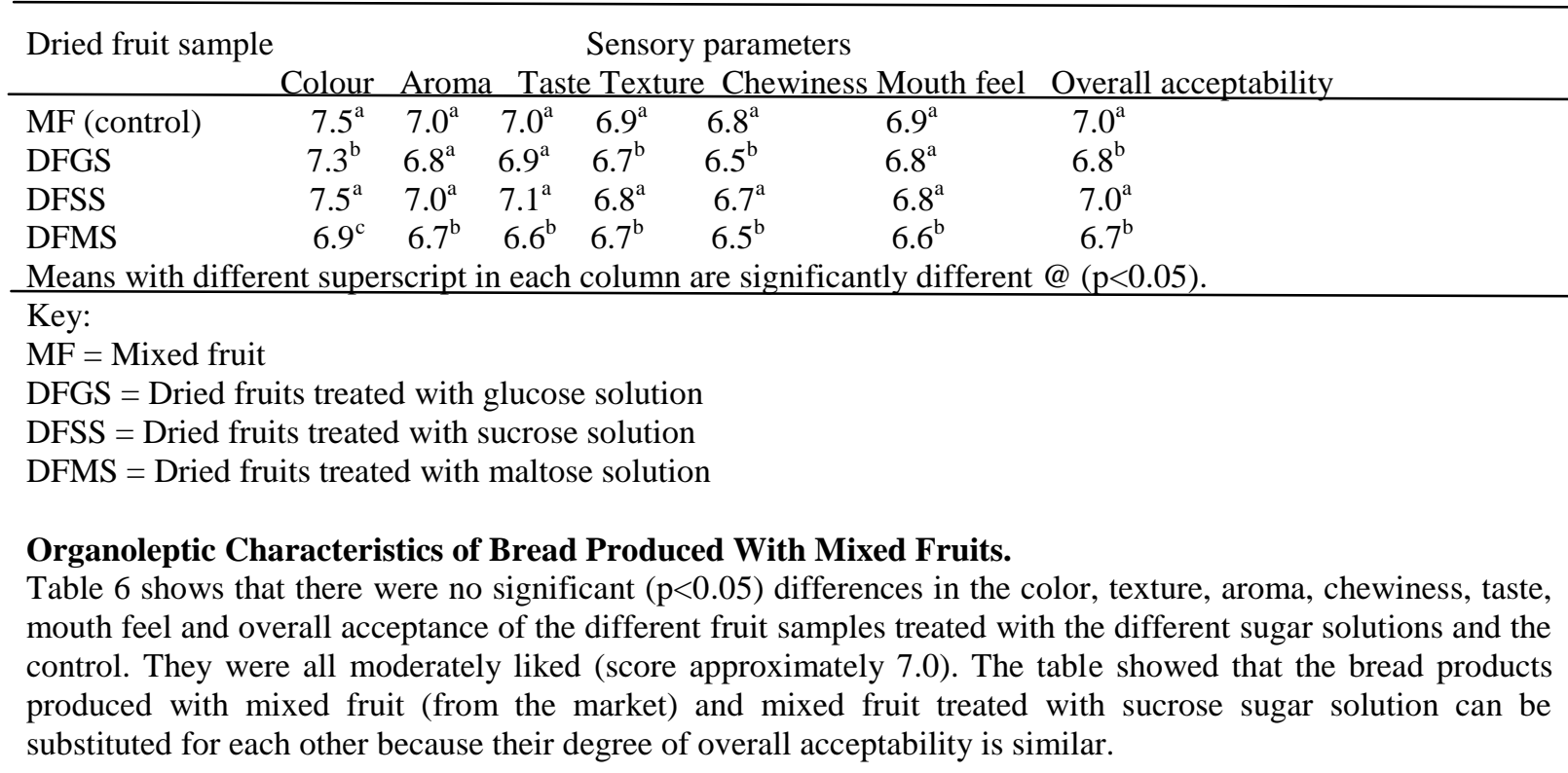

Table 6: The Mean Score for Sensory Attributes of Bread Produced With Dried Fruit Samples

\begin{tabular}{lrllllll}
\hline Dried fruit sample & \multicolumn{7}{c}{ Sensory parameters } \\
& Colour & \multicolumn{7}{c}{ Aroma Taste Texture Chewiness Mouth Feel overall } \\
BMF (control) & $6.8^{\mathrm{a}}$ & $7.4^{\mathrm{a}}$ & $7.1^{\mathrm{a}}$ & $7.0^{\mathrm{a}}$ & $7.2^{\mathrm{a}}$ & $7.1^{2}$ & $7.1^{2}$ \\
BMDFS & $6.8^{\mathrm{a}}$ & $7.3^{\mathrm{a}}$ & $7.0^{\mathrm{a}}$ & $6.8^{\mathrm{b}}$ & $7.1^{\mathrm{a}}$ & $7.1^{\mathrm{a}}$ & $7.0^{\mathrm{a}}$ \\
BMDFM & $6.6^{\mathrm{b}}$ & $7.1^{\mathrm{b}}$ & $6.7^{\mathrm{b}}$ & $6.5^{\mathrm{c}}$ & $6.9^{\mathrm{a}}$ & $6.9^{\mathrm{b}}$ & $6.7^{\mathrm{b}}$ \\
BMDFG & $6.8^{\mathrm{a}}$ & $7.3^{\mathrm{a}}$ & $6.9^{\mathrm{a}}$ & $6.6^{\mathrm{c}}$ & $6.9^{\mathrm{a}}$ & $7.0^{\mathrm{a}}$ & $6.9^{\mathrm{a}}$
\end{tabular}

Means with different superscript in each column are significantly different @ $(\mathrm{p}<0.05)$.

\section{Key:}

$\mathrm{BMF}=$ bread baked with mixed fruits

BMDFS = bread baked with dried fruits treated with sucrose solution

BMDFG $=$ bread baked with dried fruits treated with glucose solution

$\mathrm{BMDFM}=$ bread baked with dried fruits treated with maltose solution

\section{Organoleptic Characteristics of Cake Produced With Mixed Fruits}

The colour of the control sample and sample treated with sucrose solution were very much liked (score approximately 8.0), and they were significantly different from the rest of the samples. The textures of the different samples were the same, except for samples treated with maltose (Table 7). The cake product baked with the control sample had the highest overall acceptability (7.4) and was significantly similar to sample treated with sucrose, and they were significantly different from the rest of the samples. The cake sample baked with the mixed fruits treated with maltose solution had the least acceptability. From Table 7, it was observed that cake product produced with mixed fruit from the market and that produced with mixed fruits dried with sucrose solution can be substituted for each other in baking. 
Effects of Sugars on the Drying Of Some Local Fruits and Their Importance on Baked Products-

Table 7: The Mean Score for Sensory Attributes of Cake Produced With Mixed Dried Fruit Samples

\begin{tabular}{lccccccc}
\hline \multicolumn{1}{c}{ Dried fruit samples } & \multicolumn{6}{c}{ Sensory parameters } \\
& Colour & Aroma & Taste & Texture & Chewiness Mouth Feel Overall acceptability \\
\hline CMF (control) & $7.8^{\mathrm{a}}$ & $7.7^{\mathrm{a}}$ & $7.0^{\mathrm{a}}$ & $7.2^{\mathrm{a}}$ & $7.5^{\mathrm{a}}$ & $6.9^{\mathrm{a}}$ & $7.4^{\mathrm{a}}$ \\
CMDFG & $7.6^{\mathrm{b}}$ & $7.6^{\mathrm{b}}$ & $6.9^{\mathrm{a}}$ & $7.2^{\mathrm{a}}$ & $7.3^{\mathrm{b}}$ & $6.7^{\mathrm{b}}$ & $7.0^{\mathrm{b}}$ \\
CMDFS & $7.8^{\mathrm{a}}$ & $7.7^{\mathrm{a}}$ & $6.9^{\mathrm{a}}$ & $7.2^{\mathrm{a}}$ & $7.4^{\mathrm{a}}$ & $6.8^{\mathrm{a}}$ & $7.3^{\mathrm{a}}$ \\
CMDFM & $7.6^{\mathrm{b}}$ & $7.5^{\mathrm{c}}$ & $6.7^{\mathrm{b}}$ & $7.0^{\mathrm{b}}$ & $7.3^{\mathrm{b}}$ & $6.7^{\mathrm{b}}$ & $6.7^{\mathrm{c}}$ \\
\hline
\end{tabular}

Means with different superscript in each column are significantly different @ $(\mathrm{p}<0.05)$.

Key:

$\mathrm{CMF}=$ cake baked with mixed fruits sold in the market

CMDFG = cake baked with mixed dried fruits treated with glucose sugar solution

CMDFS = cake baked with mixed dried fruits treated with sucrose sugar solution

$\mathrm{CMDFM}=$ cake baked with mixed dried fruits treated with maltose sugar solution

\section{Conclusion}

\section{Conclusion And Recommendations}

Treatment of fruit with sugars prevents/ reduces the loss of nutrient during drying, facilitates drying and enhances the organoleptic properties of the dried fruit samples. Production of bread and cakes with mixed dried fruits enhanced their nutritional value, and therefore should be used in bakeries for baking bread, cakes and other confectionaries. There were no significant differences between the control sample and sample treated with sucrose in all organoleptic properties according to the test panelists.

\section{Recommendations}

The results showed that Sucrose should be recommended in the drying of fruits as it helps to prevent the loss of fruit nutrient during drying, as well as increase the organoleptic properties of the fruit treated with it. It was also recommended that dried mixed fruits treated with sugar solution be used as a substitute for the mixed fruit sold in the market, because they have the same organoleptic effects on the baked product, and the time spent in the drying of the treated fruits is lower than the untreated fruits. It is also recommended that food processors/ government should establish industries for the production of indigenous mixed dried fruits to be used both as snack, bakery and confectionery. This will not only reduce the importation of dried fruits into the country, but will also reduce postharvest losses during the glut season of fruits, boost production of fruits by farmers as well as value addition.

References

[1]. A.O.A.C (1990). Official Methods of Analysis 15th Edition. Association of Official Analytical Chemists. Washington D.C, U.S.A. pp.223-225.

[2]. Basunia, M.A. and Abe, T. (2001). Thin-layer solar drying characteristics of rough rice under natural convention. Journal of Food Engineering, 47: 295-301.

[3]. Eggleston, G., Omoaka, P.E., and Arowosegbe, A.U. (1993). Flour starch and composite bread making quality of various cassava clones. Journal Science of Food and Agriculture, 62; 49-59

[4]. Falade, k.O. and Aworh, O.C. (2005) Sensory attributes of osmotically pretreated and oven-dried African star apple (Chrysophyllum albidum) and Africa mango (Irvingia gabonensis). Journal of Food, Agriculture and Environment. vol 3(1) 90-95.

[5]. Figuerola, F., Hurtado, M.L., Esteves A., chiffelle, 1., and Asenjo, F. (2005). Fibre concentrates from apple pomance and citrus peel as potential fibre sources for enchrichment. Food chemistry ,91,395-401 .

[6]. http://www.philippineherbalmedicine.org/wiki/dried_fruit as retrieved on 25th September, 2011

[7]. Hui, Y.H. (2006). Handbook of fruits and fruit processing. Blackwell publishing professional. pp. 81

[8]. Ihekoronye, A.I and Ngoddy, P.O. (1985). Integrated Food Science and Technology for the tropics. Macmillian Publishers Ltd. London. Pp.178- 180, 305-306, 372-373.

[9]. Iwe, M.O. (2002). Handbook of sensory methods and analysis. Projoint Communication Services Ltd, Enugu.

[10]. James, S.C. (1995). Analytical Chemistry of Food. 1st ed. Chapman and Hill Printers. London. Pp. 23.

[11]. Kim, Y. (2008) Raisins are a low to moderate glycemic index food with a corresponding low insulin index. Nutr Res; 28:304-308

[12]. Nielsen, S.S. (2003). Food Analysis Laboratory Manual, Volume 1. Kluwer Academic/ Plenum Publishers. Pp.557.

[13]. Onwuka, G.I. (2005). Functional properties In: Food Analysis and Instrumentation. Naphtali Prints, Lagos. pp 134-135.

[14]. Panagiotu, N.M., Karthanos, V.T. and Maroulis, Z.B. (1998). Mass transfer modeling of the osmotic dehydration of some fruits. Int. J. Food Sci. Technol., 33: 267-284.

[15]. Sudha, M.L., Vetrimani, R. and Leelavathi, K. (2007). Influence of fibre from different cereals on the rheological characteristics of wheat flour dough and on biscuit quality. Food Chemistry, 100: 1365-1370.

[16]. Venti, C. (2002). Modified food guide pyramid for Lactovegetarians and Vegans. J.Nutr.132 (5): 1050- 1054

[17]. Willamson, G. and Carughi, A. (2010). Polyphenol content and health benefits of raisins. Nutrition Research; 30:511-519. 